\title{
Old friends and new acquaintances: Tie formation mechanisms in an inter-organizational network generated by employee mobility
}

Francois Collet and Peter Hedström

The self-archived postprint version of this journal article is available at Linköping University Institutional Repository (DiVA):

http:/ / urn.kb.se/ resolve?urn=urn:nbn:se:liu:diva-142343

N.B.: When citing this work, cite the original publication.

Collet, F., Hedström, P., (2013), Old friends and new acquaintances: Tie formation mechanisms in an inter-organizational network generated by employee mobility, Social Networks, 35(3), 288-299.

https:// doi.org/ 10.1016/j.socnet.2013.02.005

Original publication available at:

https:// doi.org/ 10.1016/j.socnet.2013.02.005

Copyright: Elsevier

http:// www.elsevier.com/

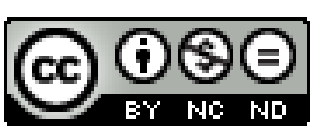




\title{
Old friends and new acquaintances: Tie formation mechanisms in an inter-organizational network generated by employee mobility ${ }^{1}$
}

\author{
Francois Collet \\ ESADE \\ Barcelona, Spain \\ Peter Hedström \\ Institute for Futures Studies \\ Stockholm, Sweden
}

\begin{abstract}
This study investigates mechanisms of tie formation in an inter-organizational network generated by the mobility of employees between organizations. We argue that information exchanges across organizations are contingent on the direction of prior employees' movements. We also assess the locality of information exchanges leading to tie formation and renewal. We analyze a data set that contains information on all organizations in the Stockholm metropolitan between 1990 and 2003. The findings highlight the importance of tie direction and the relevance of mid-range network structures in research on network dynamics and knowledge exchanges stemming from the mobility of employees across organizations.
\end{abstract}

Keywords: labour markets; mobility; interorganizatioanl network; Information flow; directed ties

\footnotetext{
${ }^{1}$ Financial support for the research and authorship of this chapter has been received from the European Research Council under the European Union's Seventh Framework Program (FP7/2007-2013)/ERC grant agreement no 324233, the Swedish Research Council, and Riksbankens Jubileumsfond.
} 


\section{Introduction}

Research on inter-firm mobility has shown that organization learn both from new hires (Rao and Drazin, 2002; Rosenkopf and Almeida, 2003; Song et al., 2003) and from employees who have moved to other organizations (Corredoira and Rosenkopf, 2010). Employees bring with them organizational routines and ties that influence organizational behavior and affect outcomes such as performance and survival (Beckman, 2006; Pennings and Wezel, 2007; Phillips, 2002, 2005; Sorensen, 1999; Wezel et al., 2006). The aggregation of individual employee movements generate inter-organizational network structures which are of relevance to creative outputs and performance (Jaffee et al., 2010; Uzzi and Spiro, 2005; Zaheer and Soda, 2009). The importance of these networks raises questions about the mechanisms governing their evolution (Zaheer and Soda, 2009). Research on labour markets has shown that the exchange of reliable and up-do-date information through social network ties is a vehicle for recruiting (Bian and Ang, 1997; Chua, 2011; Fernandez et al., 2000; Fernandez and Fernandez-Mateo, 2006; Granovetter, [1974] 1995; Mardsen and Gorman, 2001; Marin, 2012). Both employers and employees can access information about job openings and suitable candidates through the interorganizational network generated by employees’ mobility. Thus, the paths followed by employees between organizations is dependent on the past paths followed other employees who changed organization before them.

In this study we investigate tie formation mechanisms and network structure aggregate properties in a network in which nodes are organizations and ties are generated by the movement of employees between organizations. We advanced research on social 
networks in labour markets in three ways. Firstly, rather than simply consider dichotomous ties which would signal the presence or absence of a communication channel, we take into account that the value of the information that job seekers and recruiters can obtain may be contingent on whether their contact is a former or a new colleague. As a consequence the influence of past ties on the formation of new ties is contingent upon the direction past ties. Second, we consider the range within which relevant information can circulate. Prior research on job search and the labor market the focus has been largely on direct connections (Mardsen and Gorman, 2001; Mouw, 2003; Yakubovich, 2005) even if longer chains do exist (Granovetter, [1974] 1995; Piskorski, 2006). Our findings suggest that the greatest aggregate volume of information exchanges appears to take place at geodesic distance 2 and 3 even though the amount of information going through a single path declines sharply with distance. At short distances, the number of contacts is limited, but information exchanges appear to be intense. At greater distances, the number of contacts expands considerably, but the amount of information exchanged seems to be very limited. Fourth, this paper is, to our knowledge, the first study that presents data on network structure and tie formation at the level of an entire labour market. We find that despite a significant exogenous shock the structural properties of the network remain stable.

To test our hypotheses, we use a remarkable Swedish database that contains information on all organizations in the Stockholm metropolitan area during the years 1990 to 2003, all in all close to 65,000 organizations. The paper is organized as follows. We start by discussing various processes likely to influence the formation of ties in this kind of network. We then present the Stockholm database, examine the structural properties of the network, and analyze how the network changes over time. Next, we present a series of 
conditional logit models that examine the importance of various tie-formation processes. We find that endogenous tie-formation processes are sensitive to the direction of prior ties. We show that the largest volume of mobility events take place between organizations which are linked via short indirect connections ${ }^{2}$. These findings lead to a discussion of some implications for research on network dynamics and interorganizational mobility.

\section{Theory and Hypotheses}

Selecting candidates or finding suitable employers requires the evaluation of qualities that are difficult to observe and can only be revealed over time (Mardsen and Gorman, 2001). Employers and employees contact colleagues, friends, and acquaintances to obtain information (Fernandez et al., 2000; Fernandez and Fernandez-Mateo, 2006; Granovetter, [1974] 1995; Ioannides and Loury, 2004) ${ }^{3}$ The movements of employees across organizations create channels through which information can flow. Both the arrival of a new employee and the departure of a colleague create a tie across organizations. These information channels support matching processes between employers and employees in the labor market. As a result, the information channels created by the movement of employees influence future mobility patterns, which will in turn serve as information channels. In other words, employees’ paths across organizations are dependent on the paths previously followed by other employees. The value of the information that is obtained both by

\footnotetext{
${ }^{2}$ By "short" indirect connection we mean that its path length is short compared to the average path length in the network as a whole.

3 Some studies also suggest that the jobs found through such channels tend to be better than those found by other means, but the results are mixed.
} 
employees and recruiters across these channels is, however, dependent on whether the contact is a new recruit or a former colleague.

\subsection{Tie direction and endogenous tie formation}

If one considers two organizations $i$ and $j$, employees of $i$ can access information relevant to a transition to organization $j$ at time $\mathrm{t}+1$ both through former colleagues who have left $i$ to work for $j$ and through employees who used to work for $j$ and have recently joined $i$. For employees of $i$, former colleagues who are now working for $j$ are a better source of information than new colleagues who come from $j$ for two reasons. Trust relationships take time to develop (Burt, 2005). Trust ties are more likely to exist among former colleagues than between new colleagues. Second, former colleagues have up-to-date information about job opening in $j$. New colleagues coming from $j$ can also be a source of information about $j$. But these former employees have only indirect access to information about new openings in $j$. Moreover they are likely to talk about what made them leave $j$ than good reasons to join $j$. In short, from the employee's point of view, a tie from $i$ to $j$ is more conducive to a departure towards $j$ than a tie from $j$ to $i$. Table 1 presents a synthetic overview of these processes.

Table 1 and Table 2 about here

Table 2 shows how employers in $j$ can acquire information about $i$ through former colleagues and new recruits. Employers in $j$ can ask new recruits who are former employees of $i$ whether they have former colleagues who might be interested in joining $j$. New recruits 
are well positioned to provide such information because they have had the time to observe their former colleagues, build trust relationships and know who might be interested in leaving $i$. Moreover given the search costs of finding new alternatives (Simon, 1983, 1997), it is likely that employers in $j$ will look again at $i$ as a source of information for potential candidates. If employers in $j$ ask their former colleagues who now work in $i$ about potential candidates they might have up-to-date and reliable information. Yet employees who left $j$ have had limited time to get to develop trust relationships with their new colleagues and recommend someone from $i$. Moreover employees who have left $j$ for $i$ might have had good reasons to leave and may not be interested in playing the role of intermediary. In conclusion, the employer's point of view coincides with the employee's point of view: A past tie from $i$ to $j$ is more conducive to a future movement of employees from $i$ to $j$ than a past tie from $j$ to $i$.

So far we have considered only the circulation of information between two organizations through direct ties. But an information channel between two organizations may include several organizations: individuals in organization $i$ find out about jobs in $j$ from someone in organization $l$ who in turn had heard about them from someone in $k$, and so on. The shorter these paths are, the more likely it is that the information will reach someone in $i$ and lead to the establishment of a direct tie between $i$ and $j$. The arguments made about employees and employers about the circulation of information between two organizations through directed ties apply for longer path lengths. In these longer chains the role played by employers in a dyad is played by employees who receive information and referrals from other employees or have information about job openings from an employer 
other than their own. These intermediate employees play the role of surrogate employer or former colleague. Thus, we make the following hypothesis:

Hypothesis 1: Directed paths from $i$ to $j$ have a greater influence on future movements of employees from $i$ to $j$ than directed paths from $j$ to $i$.

\subsection{Sociometric distance and probability of a transfer}

In research on social networks in labor markets, the focus has been predominantly on direct ties (Marsden, 2005; Mouw, 2003). In his seminal study, Granovetter ([1974] 1995) observed that chains of length 4 are very rare. Evidence from other research streams also suggests that information exchanges decline sharply with sociometric distance. Studies of inventor citations show that at a distance 4 or greater the circulation of relevant information is very limited (Singh, 2005; Singh \& Sorenson, 2007; Sorenson et al., 2006). However, the debate about the locality of information circulation and advantages remains open. When considering structural advantages, Burt found that in most cases ego networks alone matter (Burt, 2007; Burt, 2010). No advantage accrues to being connected to brokers. There is, however, evidence that indirect ties matter for innovation. (Ahuja, 2000). Moreover Uzzi and Spiro (2005) have shown that there is a link between the small-world properties of a network and the success of cultural production teams. Finally, Reagans and Zuckerman have shown that indirect connection redundancies beyond the ego network can be associated with a power-knowledge tradeoff (Burt, 2008; Podolny, 2008; Reagans and Zuckerman, 2008; Reagans and Zuckerman, 2008a; van de Rijt et al., 2008). In all these networks, there is a tradeoff between the number of contacts that can be reached and the amount of information that can be exchanged with any given contact. Direct contacts are 
few, but exchanges may be intense. As distance increases, exchanges are sparser but contacts are more numerous. As a result, the aggregate amount of information exchanged may be greater than with direct contacts. But as one moves further away from the ego, the amount of information transmitted and the loss of relevance of the contacts will render unlikely any consequential information exchange between two nodes (Granovetter, [1974] 1995). Consequently the largest volume of information exchange may occur through indirect connections but at distances that are well below the average path length encountered in a small world network structure. In this paper we consider information exchanges across a network of former colleagues. The probability of a communication leading to a movement of employees from one organization to the other should be much higher when there is a direct tie between former colleagues. Yet the number of suitable employers that can be reached through indirect contacts is much greater. This may be associated with a high aggregate volume of information exchanges leading to movements of employees as long as the distance is not such that almost no relevant information can be exchanged. Thus we make the following hypothesis:

Hypothesis 2: The relationship between sociometric distance and the frequency with which employees move from one workplace to the other has an inverted Ushape. 


\section{Methods}

As discussed above, our focus is on the network in which organizations are nodes, and where directed links are formed when employees move from one organization to another. This network changes continuously over time, and when we refer to the network or to the ties that existed in year $t$, we refer to the networks/ties that were formed by the mobility of employees between year $t$ and $t+1$. Similarly, when we refer to the networks/ties that existed at $t-1$, these are the networks/ties that were formed between year $t-1$ and $t$.

The database we use has some unique features. It is a panel with information on the entire organizational population of the greater Stockholm metropolitan area for the years 1990 to $2003^{4}$. We have a range of demographic and socioeconomic information on the individuals employed within these organizations as well as a great deal of information on the organizations as such. The database was assembled for us by the Central Statistical Office, in Sweden, by merging a large number of administrative and population registers, something that is only possible in countries with extensive and standardized governmental registers. In Sweden, all individuals, organizations, and firms have their own unique ID numbers under which all register-based information is filed. The data is generally of very high quality and missing data are virtually nonexistent. Each year, between 15,000 and 21,000 organizations were part of the network.

\footnotetext{
${ }^{4}$ We have information on all organizations with five or more employees.
} 


\subsection{Model}

Our empirical strategy is to test our hypotheses on endogenous tie formation processes to study the potential dyads of which the network is made up. Each observation in our analysis describes a pair of organizations, and the outcome variable of interest (for the $i j$ pair) is coded 1 if someone moved from organization $i$ to organization $j$ between time $t$ and $t+1$, and 0 if that did not happen. In order to test various tie-formation hypotheses, we estimate parameters of logistic regression models of the following kind:

$$
\ln \left(\frac{p_{i j t}}{1-p_{i j t}}\right)=\alpha+\beta N_{i j t-1}+\eta H_{i j t-1}+\gamma I_{i j t-1}+\psi X_{i j t-1}
$$

where $p_{i j t}$ is the probability of a link from organization $i$ to organization $j$ to exist at time $t$; $N_{i j t-1}$ is a set of variables measuring relevant aspects of the network at $t-1, \mathrm{t}-2$ and $\mathrm{t}-3 ; H_{i j t-1}$ is a set of variables measuring how homophilous organization $i$ and $j$ are to one another at $t$ 1 ; $I_{i j t-1}$ is a set of variables measuring the incentives for individuals to move from organization $i$ to $j$ at $t-1 ; X_{i j t-1}$ is a set of variables measuring other relevant properties of organization $i$ and $j$ at $t-1$ as well as interaction variables; and $\alpha, \beta, \eta, \gamma, \psi$ are parameters to be estimated. The way in which these variables have been operationalized is described below. This type of empirical strategy, which uses dyads and logistic regression models to study tie-formation processes, is by now fairly standard in the literature (some previous examples include Gulati, 1995a; Podolny, 1994). The rarity of events and the size of our data set generate particular problems comparable to some previous studies (Sorenson and Stuart, 2001; Sorenson and Stuart, 2008). 
As will be seen below, only about 15 out of 100,000 potential dyads are actually realized, and this means that if we were to draw a random sample of the dyads, we would not fully utilize the available information (Cosslett, 1981; Imbens, 1992; King and Zeng, 2001). Moreover, in a typical year we have close to 20,000 organizations in the database, which means that there are close to 400 million potential dyads during a typical year. Using a data base of that size to estimate the type of models described above is not feasible, even with the powerful computers that we have access to.

For these two reasons, we use a so-called matched case-control design (see Breslow and Zaho, 1980; Hosmer and Lemeshow, 2000; Sorenson and Stuart, 2008). In brief, this approach implies the following. First, before doing any sampling, we create all of the variables that are to be included in the analyses. Then we select the observations to be included in the analysis. We include all dyads with the value of 1 on the outcome variable; that is, we include in the analysis all organizational pairs that are directly linked to one another. These are our "cases." Second, each of the controls $(\mathrm{Y}=0)$ for a given event $(\mathrm{Y}=1)$ data point is selected randomly. For each of these cases and for each year, we then define a control group consisting of all organizational dyads with the same combination of sector and industry characteristics as the case, but with a 0 on the outcome variable. We randomly select five organizational dyads for each case from among these matched controls. ${ }^{5}$ "Sector" matching is done using a variable distinguishing between private and public

\footnotetext{
${ }^{5}$ An advantage of the statistical model used here is that it does not require us to make any assumption about the form of the dependence between our matching variables and our dependent variables.
} 
ownership, and industrial matching is done using a variable that distinguishes between twodigit industrial codes. ${ }^{6}$

Our sampling strategy includes all events and not a subset of events. Moreover our controls are selected randomly. For these reasons, we do not run the risk of biased estimates as a result of our sampling strategy (see Sorenson and Stuart, 2008 for a similar case). To test the robustness of our results to the presence of unobserved variables that would lead to biased estimates of our structural proximity variable we ran mixlogit models for each year in our sample ${ }^{7}$. For each year we found results that were comparable to the estimates reported in the conditional logit which aggregates all years. The cases (and their controls) belonged to 893 different industries (thus defined), and all in all, 717,967 unique cases and 4,031,654 controls are included in the analyses ${ }^{8}$.

\subsection{Structural proximity}

In a network that contains a population of organizations as diverse as the one in our data set, the shortest path distance between two organizations, counted in number of steps, may not measure well the distance separating them. The likelihood of an exchange of information across the interorganizational network is dependent on the number of potential information carriers, that is, the number of individuals who move between the organizations along the path. In other words, the weights of the ties linking organizations in the network matter. Furthermore, if one organization consists of thousands of employees, for example,

\footnotetext{
${ }^{6}$ The variable that we used is based on the European Union's NACE standard. As an example of the level of precision, code 15 means "manufacture of food products, beverages, and tobacco." At the two-digit level we cannot know whether it is manufacture of meat, poultry, fish, etc. For that, the three-digit code would be required.

${ }^{7}$ The estimation of a mixed logit which would aggregate all years was not computationally feasible.

${ }^{8}$ We used the "clogit” routine in Stata 10 to estimate the parameters
} 
the information brought to this organization by an individual from another organization is not likely to reach all of its employees, and this will influence the likelihood of further transmission. The sizes of the organizations are also likely to be of importance. We define "structural proximity" as the extent to which two organizations have information channels that allow them to exchange information. To account for the amount of information that can flow across two organizations, we take into account organization size and flow intensity. Consider a network path involving $m$ organizations labeled $1,2,3, \ldots m$. We want to arrive at a proxy measure for how likely it is that individuals in organizations $2,3 \ldots m$ will find out about what is going on in organization 1 . We refer to this information as $x$. The process starts with some individuals in organization 1 learning about $x$. If we denote this number with $n_{1 x}$, the probability that a randomly selected individual in organization 1 knows about $x$ is equal to:

$$
p_{1 x}=\frac{n_{1 x}}{N_{1}}
$$

where $N_{1}$ is the total number of individuals in the organization. As detailed above, information about $x$ is assumed to spread as the result of links formed by individuals' movements from one organization to another. The expected number of individuals who know about $x$ among those who moved from organization 1 to 2 is therefore equal to $\hat{n}_{2 x}=p_{1 x} \times n_{12}$, where $n_{12}$ is equal to the total number of individuals who moved from 1 to 2 . As in the case of organization 1 , the probability that a randomly selected individual in organization 2 knows about $x$ therefore is given by: 


$$
p_{2 x}=\frac{\hat{n}_{2 x}}{N_{2}}=\frac{\frac{n_{1 x} \times n_{12}}{N_{1}}}{N_{2}}=\frac{n_{1 x} \times n_{12}}{N_{1} \times N_{2}}=\frac{n_{1 x}}{N_{1}} \times \frac{n_{12}}{N_{2}} .
$$

In the general case, the probability that information about $x$ will reach a randomly selected individual in the $j$ th organization is equal to ${ }^{9}$

$$
p_{j x}=p_{1 x} \times \prod_{i=1}^{j-1} \frac{n_{i, i+1}}{N_{i+1}}
$$

If we make the simplifying assumption that $p_{1 x}$ is the same in all network paths, we can use the so-called Dijkstra (1959) algorithm to arrive at a relevant structural proximity measure. The appropriate weight for each edge of the network is then simply the inverse of $n_{i, j+1} / N_{i+1}$, and the "length" of the shortest weighted path between organization $i$ and $j$ found by the Dijkstra algorithm provides an estimate of how likely it is that information will flow from $i$ to $j$. Since the Dijkstra algorithm finds the path with the shortest additive sum of weights, to estimate $p_{j x}$ as given by Equation 1, the input into the algorithm must be the logarithm of $N_{i+1} / n_{i, j+1}$. The exponentiated sum of weights calculated along these "shortest" paths is the measure of structural proximity used in the logistic regression models in Table $6 .{ }^{10}$ Needless to say, the focus on the shortest paths does not mean that we believe that information only flows along these paths. We use this structural proximity measure as a proxy for the ease by which information flows from one organization to another, and for the reasons given above, we believe that this is a more appropriate measure of structural proximity than the unweighted geodesic distance.

\footnotetext{
9 Thus, as applied to our data, we assume that the diffusion of information takes place during a single calendar year. It would have been possible to make a different assumption, but it would have made the estimation procedure considerably more difficult, and it is unlikely that it would have had much impact on the results.

${ }^{10}$ We used the implementation of the Dijkstra algorithm found in the so-called C++ Boost graph library found at www.boost.org.
} 


\subsection{Control variables}

We do not think that there is any single overarching principle or mechanism that guides the evolution of social networks, be it utility maximization, as is often assumed in the recent economics literature on networks (see e.g., Jackson, 2008), or law-like preferential attachment mechanisms as is often assumed in the recent physics literature on social networks \{Barabási, 1999 \#568\}. Although such mechanisms are important, they only provide pieces of the causal puzzle. The kind of network we focus on here is the result of the actions of thousands of employers and employees. The links in the network are formed through a complex process in which individuals and vacant jobs find one another, and a range of different processes are likely to be at work.

McPherson et al's (2001) extensive review of the homophily literature shows that contacts between similar people typically occur at a much higher rate than contacts between dissimilar people, and that this holds true for a range of different attributes such sex, ethnicity, age, and education. Similar others are perceived as offering relevant information (Festinger, 1954). Social identity group membership leads agents to collaborate with similar others and compete with dissimilar others (Buchan et al., 2002; Mollica et al., 2003; Reagans et al., 2005). Self-verification, the yearning to be understood by others as we understand ourselves, also leads to homophilous tie formation (Swann et al., 2000). Both employees and employers are embedded in macrostructures summarized by aggregate statistics such as the proportion of women or foreign-born employees. These macrostructures influence microbehavior at the level of employees such as homophilous tie

formation. This suggests that a link from organization $i$ to $j$ is more likely to form if employees in $i$ and $j$ are similar to one another in terms of their sociodemographic 
characteristics. For example employees embedded in an organization with a large proportion of migrants are likely to recruit more migrant employees (see Fernandez and Fernandez-Mateo, 2006 for an in-depth exploration of hiring mechanisms).

Networks are also prisms through which actors evaluate one another (Podolny, 2001, 2005). When actors use information about existing network connections to decide whom to connect with, a different kind of endogenous process is at work than the one just discussed. If individuals in organization $i$ observe that individuals from other organizations move to or seek employment in organization $j$, all else being equal, their interest in $j$ is likely to increase. Therefore, we expect the indegree of organization $j$ to be positively related to the probability of a direct link being formed from $i$ to $j$ at the next point in time.

Similarities at the organizational level are also likely to be important for the dynamics of the network. One crucial organizational-level property is the type of work carried out in the organizations. As emphasized by Becker (1962), Neal \{, 1995 \#915\}, and others, the specificity of the skills acquired at work is likely to be of crucial importance for individuals' mobility patterns. Within certain industries, sectors, or large multiorganizational firms, individuals can move from one organization to another and make use of most of their acquired skills. Were they to move to another industry, sector, or firm, this would no longer be the case, however, and they would then risk a loss in earnings. For this reason we should expect that a link from organization $i$ to $j$ is more likely to form if the two organizations belong to the same industry, sector, and/or multi-organizational firm. ${ }^{11}$ Geographic proximity is also likely to be of importance for interorganizational networks

\footnotetext{
${ }^{11}$ In this paper, an "organization" is defined as a work establishment with a unique geographic location. This means that a "firm" can consist of more than one "organization." If a bank has offices located in different parts of a city, for example, the bank is the "firm" and the offices are the "organizations." A "multiorganizational" firm is thus a firm with two or more organizations.
} 
like this. As Stouffer (Stouffer, 1940) once expressed it, the greater the geographic distance between two actors, the greater are "the intervening opportunities" to find other actors to associate with. Hence, the shorter the geographic distance is between organizations $i$ and $j$ is more likely a link will form between them. ${ }^{12}$

An important assumption in much of the recent economics literature on networks is that the formation of a network tie is the outcome of some form of utility-maximizing strategies on the part of the actors involved (e.g., Jackson, 2008). That is, while much of the organizational and sociological literature view networks as unintended byproducts of activities concerned with non-networking activities, in most of the economics literature the formation and dissolution of network ties are analyzed as intended outcomes of individuals’ rational choices. Although we believe that an approach that focuses exclusively on such processes is likely to disregard much of what is essential for understanding the dynamics of networks, incentives are of obvious importance, particularly for the type of networks analyzed here. Previous research as well as everyday experience clearly suggest that job mobility decisions are influenced by prospective gains in earnings and status (Manning, 2003) (Holmlund, 1984). We therefore expect that the probability of a link being formed from organization $i$ to organization $j$ will increase with the pay in $j$ and decrease with the pay in $i$. Finally the probability of a transition of employees between two organizations increases with their sizes. For each additional employee of $i$, the probability of a transition increases with the size of $j$. We measure this effect by introducing the size of each organization and their products as controls.

\footnotetext{
12 See Kono, Palmer, Friedland and Zafonte (Kono, Palmer, Friedland and Zafonte,1998), Owen-Smith and Powell (Owen-Smith and Powell,2004), and Sorenson, Rivkin and Fleming (Sorenson, Rivkin and Fleming,2006) for examples that testify to the importance of spatial factors for various organizational processes.
} 


\section{Results}

\subsection{Global network properties}

Table 3 presents various statistics describing the structural properties of this network. These descriptive statistics are based on all organizations and not on the smaller case-control subsample which will be used for estimating the parameters of the logistic regression models. The first panel of Table 3 shows that the structure of the network was rather stable during this time period. This is somewhat surprising given the fact that this was a highly turbulent period in the Stockholm labor market. The unemployment rate among 16- to 64year-olds, for example, increased sharply from 1 percent in 1990 to close to 7 percent in 1993, and by the end of our period it was back to a more typical level of 3 percent. ${ }^{13}$

\section{Table 3 about here}

Despite these ups and downs in the labor market, the average degree of the organizations (i.e., the average number of other organizations to which an organization is linked) did not vary much from one year to the next. Each year, the average organization was linked to 3-4 other organizations. The between-organization variation in degrees was considerable throughout the period, however, and the degree distribution was highly skewed. ${ }^{14}$ While the vast majority of organizations were linked to two or fewer

\footnotetext{
${ }^{13}$ These unemployment figures are based on Statistics Sweden's annual so-called ALU surveys.

${ }^{14}$ In the degree interval 3 to 350, the degrees are approximately power-law distributed with an exponent of 2.0.
} 
organizations, some organizations were like network hubs connected to numerous other organizations. ${ }^{15}$

As shown in Table 3, despite the fact that this is a low-density network, each year almost all organizations-between 96 and 99 percent-belonged to one giant interconnected component. The observed clustering coefficients are about 10 to 20 times larger than the clustering coefficients one would have expected in a random network of this size and density. ${ }^{16}$ Table 3 also shows that the average geodesic path is short, comparable to that of a random network. ${ }^{17}$ Although the network is a low-density network and consists of more than 15,000 nodes, on average, any randomly selected organization was only 5 to 6 links from any other randomly selected organization. These structural properties are characteristic of small-world networks (Watts and Strogatz, 1998).

Table 3 also shows that the network is characterized by positive assortative mixing, that is, highly connected organizations tend to be connected to other highly connected organizations. The degree correlations are rather weak, however, and fall in the range .02 to .08. This suggests that there were numerous exceptions to the positive assortative pattern. ${ }^{18}$

\footnotetext{
${ }^{15}$ Organizations with a high degree were typically large, often with more than 2,000 employees. Among the high-degree organizations we find temporary work agencies, a few large healthcare organizations as well as private telecom and pharmaceutical firms.

${ }^{16}$ The expected value of the clustering coefficient in a random Erdös/Rényi network is equal to $2 M /(N \times[N-1])$ where $M$ is the number of edges and $N$ is the number of nodes. For the network analyzed here, the expected value of the clustering coefficient varies between a low of .00028 in 1991 and a high of .00041 in 2000, which should be compared with the observed values, which vary between .032 and .047 . The ratio of observed clustering coefficient $(C)$ over the clustering coefficient of a random network $\left(\mathrm{C}_{\mathrm{r}}\right)$ is sensitive to network size. To correct for this distortion we present the size-adjusted clustering ratio $\mathrm{C}_{\mathrm{ra}}=(1 / \mathrm{N}) *\left(\mathrm{C} / \mathrm{C}_{\mathrm{r}}\right)$ with $\mathrm{N}$ denoting network size (Gulati, Stych and Tatarynowicz,2009).

17 To account for distortion resulting from network size, we calculate the adjusted shortest path ratio $\mathrm{L}_{\mathrm{ra}}=\mathrm{Ln}(\mathrm{N}) *\left(\mathrm{~L}_{\mathrm{L}} \mathrm{L}_{\mathrm{r}}\right)$ with $\mathrm{L}_{\mathrm{r}}$ denoting the average shortest path for a random network of the same size and $\mathrm{N}$ network size ibid..

${ }^{18}$ In comparison to a random network of the Erdös/Rényi kind, the extent of assortative mating is high, however, since in such a network the expected degree correlation is equal to zero see (Newman,2002). If we control for organizational size by examining the degree-divided-by-size correlations, the correlation
} 
Since mobility patterns and the interorganizational networks they bring about are highly dependent on the educational levels of employees and the educational requirements of employers, the network statistics in the second and third panel of Table 3 distinguish between the networks formed by the mobility of less and more highly educated individuals. ${ }^{19}$ These education-specific networks differ from one another in certain respects. The network of the more highly educated is more locally clustered than the network of the less educated, and the average path distance tends to be shorter in the network of the more highly educated. The small-world properties are thus more pronounced in the network of the more highly educated than in the network of the less educated. The main message communicated by all of these statistics is that of a small-world network with higher clustering and short path length during the period 1991-1993.

\subsection{Tie formation}

Endogenous tie formation processes imply that the length of the shortest path from organization $i$ to $j$ at time $t-1$ should be negatively related to the probability of a link from $i$ to $j$ at time $t$. Figure 1 provides a first rough test of this proposition.

Figure 1 about here

coefficients increase somewhat (they are in the range .027 to .145). This suggests that the observed assortative mixing is not due simply to the skewed size-distribution of organizations.

19 "Less" education here refers to less than 12 years of education and "high" education to 12 years or more. We chose this cut-off point because in Sweden it usually takes 12 years to complete a high-school degree. The nodes of these networks consist of the subset of organizations from Panel 1 that either had at least one less (more) highly educated employee or received at least one less (more) highly educated employee from another organization during the year in question. As in the case of the overall network, a link is formed when a less (more) highly educated individual moves from one organization to another and the direction of the link depends on the direction of the move. 
The dashed straight line in Figure 1 indicates the average probability of a tie being formed in the organizational population as a whole, and the dotted line shows how this probability varies with path distance. Organizations that were directly linked to one another at $t-1$ were 1027 times more likely to be directly linked to one another at time $t$ than was the average organization. Organizations that were two path distances apart were 33 times more likely to be linked to one another, and those at path distance three were more than six times as likely as the average organizations to be linked to one another at $t$. As discussed above, however, the network dynamics we observe are likely to be the outcome of several different tieformation processes operating jointly. This means that the pattern shown in Figure 1 is most likely due to more than endogenous tie-formation processes alone. To take other effects into account, we estimate a series of conditional logit models of the kind described above.

The outcome variable in the logistic regression models records whether or not two organizations, $i$ and $j$, were directly linked to one another, and the covariates included in the baseline models provide a foundation for testing our hypotheses. The parameter estimates of our baseline models are found in Table 5, and a description of the variables is found in Table 5. As can be seen in Table 5, the fit of the models as measured by pseudo $R^{2}$ are reasonably good, and all covariates have significant effects, and the main effects are in the expected directions. We start by discussing the first model in some detail, and thereafter we briefly highlight how Models 4 to 5 differ from Model 1. As mentioned above, the matched case-control design means that we control for the matching variables in all models, that is, for the public/private and the industrial sector. In addition, given the considerable variation 
that exists in organizational size, we control for size by including in all models the size of organization $i$, the size of organization $j$, and their product. The first three variables in Table 5 are these size-related control variables and, as expected, the parameter estimates are positive and highly significant.

Table 5 and 6 about here

The next set of variables in Table 5 concerns the hypothesized homophily effects. The results suggest that the gender and ethnic composition of organizations is important for the formation of network ties. More precisely, Model 1 shows that the larger the difference in the percentage of women in two organizations, the less likely it is that a link will be formed between them. Ethnic differences also matter, and the greater the difference between two organizations in the percentage of foreign-born employees, the less likely it is that a link will form between them. A comparison of the odds ratios, that is, the exponentiated values of the logistic regression coefficients, suggests that gender differences are of greater consequence for the formation of network ties than are ethnic differences. The odds ratio for the gender variable is $.12\left(\approx \mathrm{e}^{-2.110}\right)$, which suggests that the odds of a link forming between an all-female organization and an all-male organization is only 12 percent of the odds had they had the same gender composition. The odds ratio for the ethnicity variable is .74, which suggests that the odds of a link forming between an organization with only foreign-born employees and an organization with only Swedishborn employees is 74 percent of the odds had they had the same percentage of foreign-born employees. The ethnic composition of organizations thus also has a substantial effect on the 
formation of network ties, but the effect, as measured by the odds ratio, is smaller than for gender.

The results also suggest that age differences between employees in the organizations matter. The effect of the age difference is negative as expected, and it is highly significant. The odds ratio is .95, which implies that if there is a one-year difference in average age between two organizations, the odds of a link forming between them is .95 of what it would have been had the employees been of the same average age. Differences in average years of schooling also matter. As expected, the more different two organizations are in terms of the educational levels of their employees, the less likely it is that a link will be formed between them. The odds ratio is .62, which suggests that a one-year difference in the average educational level between two organizations reduces the odds of a link between them to 62 percent of what it would have been had they had the same average education. Although it is always difficult to assess the relative importance of different variables, these results seem to suggest that educational differences were of greater consequence for the interorganizational network than were age differences. In order to achieve the same change in the odds ratio as that which results from a one-year difference in average schooling, the average age must differ by 8 years. Since the standard deviations of these two variables are 1.04 and 4.71, such a difference in average age is much less frequently observed than a one-year difference in average education (we will return to the importance of education when discussing Model 4 and 5).

The next two variables examine the effects of homophily/proximity at the organizational level. More specifically, they examine how tie formation is influenced by the organizations' being part of the same multi-organizational firm, and by being located in the 
same municipalities. As expected, both variables have positive effects on the probability that a tie will form. The odds ratio is much higher for the former variable, however, 13.12 versus 1.90, which suggests that being part of the same firm is far more important than being located in the same municipality. ${ }^{20}$

Variables 10 and 11 examine the importance of incentives. These variables measure the average earnings in organization $i$ and $j$ (in thousands of SEK). As expected, the probability of a link from $i$ to $j$ decreases with the pay level in $i$ and increases with the pay level in $j$. In absolute terms, the regression coefficient for the pay in $i$ is about three times larger than the regression coefficient for the pay in $j$. This suggests that employees' mobility patterns respond more to a given change in the pay in their own organization than to corresponding changes in other organizations. The odds ratios are small, .98 for the pay in $i$ and 1.001 for the pay in $j$. But the salary variables have very high variance, with standard deviations greater than 100. The multiplicative change in the tie-formation odds for a one standard deviation increase in the wage level of organization $j$ is $1.38\left(1.003^{\wedge} 108\right)$ which is important. The results are not robust, however, for the variable measuring financial incentives in $j$. The sign of the coefficient for this variable changes across models. $^{21}$

Based on Podolny’s (2001) discussion of networks as “prisms” and Barabasi’s work on preferential attachment (e.g., Barabasi, 2003), we expected to find that employees in

\footnotetext{
${ }^{20}$ The limited impact of the spatial variable is likely due to the way in which we have designed this study. Had we focused on a larger geographic area than Stockholm county, spatial distances would undoubtedly have appeared more important.

${ }^{21}$ Since the crude difference in average pay is a rather blunt incentive measure, we also tried a somewhat more refined measure that took into account the human-capital characteristics of the employees. Within each organization we regressed earnings on age, sex, education, and ethnicity, and we used the average withinorganization residuals from these regressions as a measure of whether or not an organization was a high- or a low-paying organization given the composition of its employees. Qualitatively, the results were very similar to those reported here, however.
} 
organization $i$ would be more attracted to organization $j$ if they observed that individuals from other organizations moved to $j$. We tested this hypothesis by including a variable measuring the indegree of organization $j .{ }^{22}$ As can be seen in Table 5 , the effect of this variable is significant and it has the expected positive sign. The odds ratio is only 1.002 but variance is large. For one standard deviation of the odd degree, the odds are multiplied by $47\left(1.002^{\wedge} 194\right)$.

The last two variables in Model 1 test the relationship between structural proximity and tie formation. Combining path length, the size of the nodes, and the width of the path into a measure of structural proximity described in the methods section, we expected this variable to be positively related to the probability of a link being formed at the next point in time. The effects of structural proximity, calculated along the path from $i$ to $j$ and along the path from $j$ to $i$, are highly significant and have the expected positive signs. Since this measure of structural proximity is not easy to grasp at an intuitive level, it is hard to judge whether the magnitude of the effects are important from a substantive point of view. As can be seen in Table 4, a typical variation in this variable (as measured by the standard deviation) is about .08 . The odds ratio associated with a .08 unit change in the structural proximity variable $i \rightarrow j$ is about 1.95 . This should be compared with the odds ratio of .77 for a typical variation in the gender composition and the odds ratio of .62 for a typical variation in the average level of education. The magnitude of the structural proximity effects thus appears important from a substantive point of view and relatively high in relation to the effects of the other variables.

\footnotetext{
22 It should be observed that "indegree" is here measured as the number of individuals who moved to organization $j$ from organizations other than $i$.
} 
Model 2 in Table 5 is identical to Model 1 with one important difference. When estimating this model, we excluded all organizational pairs that were directly linked to one another at time $t-1$. Thus, while the outcome event analyzed in Model 1 is the formation of a new tie or the maintenance of an existing tie, the outcome event focused upon in Model 2 is the establishment of a new tie. What is particularly interesting here is the considerable robustness of the results. The Model 2 estimates are virtually identical to the Model 1 estimates, and this suggests that the processes that explain the maintenance of existing ties are not that different from the processes that explain the establishment of new ties.

The variables included in Models 4 and 5 are identical to those in Model 1 and 2, but Model 4 analyzes the tie-formation process in the network of the less educated, and Model 5 analyzes the tie-formation process in the network of the more educated. The most notable difference between these groups is found for the ethnic composition variable. The odds ratio is very close to 1 (.92) for the group with a higher level of education. The odds ratio for the group with lower education is lower (.77) but still greater than in Model 1. This result suggests that there are some interactions between these two groups. There are some differences between these groups such as firm boundaries, and geography appears to be more important for the formation of ties in the network of the less educated. However, the

most important finding is the considerable similarity between these results and those of Model 1 and 2.

\subsection{Directed Paths}

In Model 1, the odds ratio associated with a .08 unit change (one standard deviation) in the structural proximity $i \rightarrow j$ variable is 1.95 . The odds ratio for the same change in structural 
proximity $j \rightarrow i$ is 1.69 . These results provide support for Hypothesis 1: structural proximity $i \rightarrow j$ at time t- 1 has a greater influence than structural proximity $j \rightarrow i$ at time $t-1$ on the formation of a directed tie $i \rightarrow j$ at time t. In Model 3, we introduce lagged structural proximity variables at $\mathrm{t}-2$ and $\mathrm{t}-3$. The results are summarized in Figure 2. The effect of structural proximity declines with time. The independent effect of lagged structural proximity at $\mathrm{t}-2$ and $\mathrm{t}-3$ is lower than the effect of structural proximity at $\mathrm{t}-1$ but remains significant. In Model 3, the odds ratio for a typical variation of structural proximity $i \rightarrow j$ at $\mathrm{t}-1$ is 1.69 . By comparison, the odds ratio for the same variation at $\mathrm{t}-2$ is about 1.32 and 1.23 at t-3. For structural proximity $j \rightarrow i$, the amortization follows a similar pattern although the effects are smaller. At $\mathrm{t}-1$ and $\mathrm{t}-2$ the odds ratio are 1.55 and 1.24 and at $\mathrm{t}-3$ the odds ratio is only 1.05 . Overall these results confirm that structural proximity $i \rightarrow j$ has a greater effect than structural proximity $j \rightarrow i$ on future flows of employees from $i$ to $j$.

Figure 2 about here

\subsection{Distribution of dyads and events}

In order to fully appreciate the importance of the existing network structure for its dynamics, it is important also to consider the numbers under risk. A certain type of tie may be of considerable importance for the formation of new ties, but the type of tie in question may be so rare that it will have little influence on the overall dynamics of the network. The two graphs in Figure 3 highlight the importance of this distinction. 
Figure 3 about here

Figure 3 shows the distribution of tie-formation events and the distribution of dyads at different path lengths across all years. In total there are about 1.6 billion shortest path values and one million ties between workplaces for the period considered. Very few organizations are directly linked to one another (see the dashed line), but as the logistic regression results suggests, when two organizations are close to one another, the probability of a direct link being formed between them is considerable. As a result, a significant number of tie-formation events occur at this distance (see the solid line). When two organizations are two or three path distances apart, the probability of tie formation is lower, but there are many more organizations at these distances. We observe a greater total number of connections formed at distance 2 and 3 than at distance 1 . In the path-distance interval 4 to 6 , the number of dyads increases dramatically, but at the same time the probability of tie formation falls, and the combined result is that the number of tieformation events declines. For example, although the most common geodesic distance is as low as 5, only .2 percent of the ties are formed at this distance. At distance 7 and above, we are in the upper tail of the dyad distribution; there are very few dyads in this range, and the probability of ties being formed between them is extremely small. Consequently, almost no events take place in this region of the network. These results provide support for Hypothesis 2: the relationship between the frequency with which employees move from one workplace to the other and distance in the network has an inverted U-shape. 


\section{Discussion and Conclusion}

This study examines the social processes that underpin endogenous tie formation and investigates the locality of information circulation in a network generated by the mobility of employees across organizations. We find that a past directed path between two organizations is more likely to lead to the formation of a tie in the same direction than to a tie in the opposite direction. Two types of actors, employers and employees, use the same channels, each for their own purposes and the formation of new ties is the result of matching processes between them. For employees, former colleagues are a more valuable source of information because they have had time to develop trust relationships. For employers, new recruits are a better source because they are better positioned to identify potential candidates than are former colleagues. These findings have implications for research on interorganizational mobility and knowledge transfers. With a few exceptions, most studies have concentrated on knowledge acquired through hiring (Rao and Drazin, 2002; Rosenkopf and Almeida, 2003) or the damage resulting from the departure of some employees (Phillips, 2002; Wezel et al., 2006). Recently a number of studies have explored how an organization can learn from the employees who move to other organizations (Agrawal et al., 2006; Corredoira and Rosenkopf, 2010; Somaya et al., 2008). Our results suggest that the processes of information exchanges are contingent on the identity (former colleagues or new hires) of the contacts. Further research should explore whether other social processes such as information exchanges between scientists in an innovation network lead to similar asymmetries. 
The results on the locality of information circulation are consistent with other studies on labor markets and patent citations, which find that chains of length 4 or greater are very rare (Granovetter, [1974] 1995; Singh, 2005; Singh and Sorenson, 2007; Sorenson et al., 2006). But we also observe that the distribution of matches between employees and employers does not decline monotonously with distance but is rather bell-shaped. The greatest number of connections occurs at distance 2 and 3. Very few organizations at distance 4 or 7 ever connect. These results call for further research on innovation and mobility for a number of reasons

For one thing, the range at which information circulates across organizations is still not well understood. In research on the links between interorganizational networks and performance outcomes, there is evidence that small-world network structures can be associated with performance (Uzzi and Spiro, 2005). Yet there seems to be no relation between the small-world properties of inventors' network and innovation (Fleming et al., 2007). Some measure redundancy using global measures (Jaffee et al., 2010), while others, in line with Burt's finding on second hand brokerage (Burt, 2007; Burt, 2010), use local measures (Zaheer and Soda, 2009). If an organization obtains more information through indirect contacts at distance 2 or 3 , it may be important to consider indirect connections redundancy suggested in some models (Burt, 2008; Reagans and Zuckerman, 2008) but within a range that is well below global network structures. Our results suggest that greater attention should be paid to medium range structures in research on the links between networks and information exchanges and their associated outcomes.

In the analyses presented in this paper, tie formation is explained by a number of social mechanisms that operate conjointly rather than by an overarching mechanism such as 
utility maximization. If, for example, individuals have strong preferences for working with similar others, being structurally close to a dissimilar organization may not matter for the probability of a link being formed. Furthermore, since homophily is important for information-based reasons as well, if two organizations are similar, homophily-based ties may be a privileged source of information, making structural proximity less relevant. Similarly, if two organizations are so far apart that information is unlikely to flow between them, the attributes of the organizations should have less influence on the probability of tie formation. Future research should explore how these mechanisms interact.

The network analyzed in this study comprises organizations that are dramatically different from others in their purpose, size and structure and the volume of individuals moving across them also varies considerably. Our measure of structural proximity accounts for some of this diversity by incorporating organizational size and flow density. These dimensions are relevant to research on interorganizational knowledge flows. Innovation scholars have investigated the interaction of social distance with knowledge complexity, geographic distance, and organizational affiliation (Singh, 2005; Singh and Sorenson, 2007; Song et al., 2003; Sorenson et al., 2006). But they have not taken into account the size of the organizations along the path that links them, or the strength of ties along paths of length greater than 1 . Future research awaits studies which incorporate these dimensions to model knowledge exchanges in a more realistic fashion.

This study makes an important contribution to research on interorganizational networks and mobility by showing that most information exchanges and mobility events occur through short indirect connections. This result suggests that research should pay greater attention to medium-range structures between ego networks and overall network 
characteristics. We also contribute to research on interorganizational mobility by showing that information exchanges across organizations through former colleagues are contingent on the direction of prior employees' mobility. We hope that these findings will stimulate further research that will recognize the importance of tie direction and the relevance of midrange network structures to further our understanding of network dynamics and knowledge exchanges stemming from employees mobility across organizations.

\section{References}

Agrawal, A., Cockburn, I., McHale, J., 2006. Gone but not forgotten: knowledge flows, labor mobility, and enduring social relationships. Journal of Economic Geography 6, 571-591.

Ahuja, G., 2000. Collaboration Networks, Structural holes and Innovation: A longitudinal study. Administrative Science Quaterly 45, 425-455.

Austin, J.L., 1962. Sense and Sensibilia. Oxford University Press, Oxford and New York.

Barabasi, A.L., 2003. Linked: How everything is connected to everything else and what it means.

Beckman, C., 2006. The influence of founding team company affiliations on firm behavior.

Academy of Management Journal 49, 741-758.

Bian, Y., Ang, S., 1997. Guanxi networks and job mobility in China and Singapore. Social Forces 75, 981-1005.

Breslow, N.E., Zaho, L.P., 1980. Statistical Methods in Cancer Research. International Agency on Cancer.

Buchan, N.R., Croson, R.T.A., Dawes, R.M., 2002. Swift Neighbors and Persistent Strangers: A

Cross-Cultural Investigation of Trust and Reciprocity in Social Exchange. UChicago Press, pp. 168-

206.

Burt, R.S., 2005. Brokerage and Closure: An Introduction to Social Capital. Oxford University Press. Burt, R.S., 2007. Second-Hand Brokerage: Evidence on the Importance of Local Structure for Managers, Bankers and Analysts. Academy of Management Journal 50.

Burt, R.S., 2008. Information and structural holes: comment on Reagans and Zuckerman. Industrial and Coporate Change 17, 953.

Burt, R.S., 2010. Network Neighbors. Oxford University Press.

Corredoira, R.A., Rosenkopf, L., 2010. Should Auld Acquaintance Be Forgot? The Reverse Transfer of Knowledge through Mobility Ties. Strategic Management Journal 31, 159-181.

Cosslett, S.R., 1981. Maximum likelihood estimator for choice-based samples. ECONOMETRICA 49, 1289-1316.

Chua, V., 2011. Social networks and labour market outcomes in a meritocracy. Social Networks 33, 1-11.

Dijkstra, E.W., 1959. A note on two problems in connexion with graphs. Numerische mathematik 1, 269-271.

Fernandez, R., Castilla, E., Moore, P., 2000. Social capital at work: Networks and employment at a phone center. American Journal of Sociology 105, 1288-1356. 
Fernandez, R., Fernandez-Mateo, I., 2006. Networks, race, and hiring. American sociological review 71, 42-71.

Festinger, L., 1954. A theory of social comparison processes. Human Relations 7, 117-140.

Fleming, L., King, C., Juda, A.i., 2007. Small Worlds and Regional Innovation. Organization Science 18, 938-954.

Granovetter, M., [1974] 1995. Getting a job: A study of contacts and careers. University of Chicago Press, Chicago and London.

Gulati, R., 1995a. Social structure and alliance formation patterns: A longitudinal analysis.

Administrative Science Quaterly 40, 619-652.

Gulati, R., Stych, M., Tatarynowicz, A., 2009. The Dynamics of Social Structure: The Emergence and Decline of Small Worlds, Organization Science Special Issue Conference on Dynamic networks, Milan.

Holmlund, B., 1984. Labor mobility: Studies of labor turnover and migration in the Swedish labor market. Industrial Institute for Economic and Social Research.

Hosmer, D.W., Lemeshow, S., 2000. Applied Logistic Regression. Wiley. Imbens, G.W., 1992. An efficient method of moments estimator for discrete choice models with choice-based sampling. Econometrica 60, 1187-1214.

loannides, Y.M., Loury, L.D., 2004. Job information networks, neighborhood effects, and inequality. Journal of Economic Literature 42, 1056-1093.

Jackson, M.O., 2008. Social and Economic Networks. Princeton University PRess.

Jaffee, J., McEvily, B., Tortoriello, M., 2010. Not All Ties Are Equal: Temporal and Historical Dynamics of Professional Networks on Law Firm Growth, Working Paper.

King, C., Zeng, L., 2001. Logistic Regression in Rare Events Data. Political Analysis 9 137-163.

Kono, C., Palmer, D., Friedland, R., Zafonte, M., 1998. Lost in Space: The Geography of Corporate Interlocking Directorates 1. American Journal of Sociology 103, 863-911.

Manning, A., 2003. Monopsony in motion: Imperfect competition in labor markets. Princeton Univ Pr.

Mardsen, P.V., Gorman, E.H., 2001. Social Networks, Job Changes and Recruitments, in: Berg, I.E., Kalleberg, A.L. (Eds.), Sourcebook of Labor Markets: Evolving Structures and Processes. Springer, pp. 467-502.

Marin, A., 2012. Don't mention it: Why people don't share job information, when they do, and why it matters. Social Networks 34, 181-192.

Marsden, P.V., 2005. The sociology of James S Coleman. Annual Review Of Sociology 31, 1-24.

McPherson, M., L. Smith-Lovin, J. M. Cook, 2001. Birds of a Feather: Homophily in Social Networks. Annual Review of Sociology 27, 415-444.

Mollica, K.A., Gray, B., Trevino, L.K., 2003. Racial Homophily and Its Persistence in Newcomers' Social Networks, pp. 123-136.

Mouw, T., 2003. Social capital and finding a job: Do contacts matter? American sociological review 68, 868-898.

Newman, M.E.J., 2002. Assortative Mixing in Networks. Physical Review Letters 89.

Owen-Smith, J., Powell, W., 2004. Knowledge networks as channels and conduits: The effects of spillovers in the Boston biotechnology community. ORGANIZATION SCIENCE 15, 5-21.

Pennings, J.M., Wezel, F.C., 2007. Human capital, inter-firm mobility and organizational evolution. Edward Elgar, Cheltenham.

Phillips, D.J., 2002. A genealogical approach to organizational life or chances: The parent-progeny transfer among silicon valley law firms, 1946-1996. Administrative Science Quarterly 47, 474-506. Phillips, D.J., 2005. Organizational genealogies and the persistence of gender inequality: The case of Silicon Valley law firms. Administrative Science Quarterly 50, 440-472. 
Piskorski, M.J., 2006. LinkedIn (TN) (A) and (B). Harvard Business School Teaching Note 708-406. Podolny, J.M., 1994. Market Uncertainty and the Social Character of Economic Exchange.

Administrative Science Quarterly 39, 458-483.

Podolny, J.M., 2001. Networks as the pipes and prisms of the market. American Journal of Sociology 107, 33-60.

Podolny, J.M., 2005. Status Signals. Princeton University Press, Princeton.

Podolny, J.M., 2008. Resurrecting images from the past? Comment on Reagans and Zuckerman, Industrial and Corporate Change. Oxford Univ Press, p. 971.

Rao, H., Drazin, R., 2002. Overcoming resource constraints on product innovation by recruiting talent from rivals: A study of the mutual fund industry, 1986-94. Academy of Management Journal 45, 491-507.

Reagans, R., Argote, L., Brooks, D., 2005. Individual Experience and Experience Working Together: Predicting Learning Rates from Knowing Who Knows What and Knowing How to Work Together, pp. 869-881.

Reagans, R.E., Zuckerman, E.W., 2008. Why knowledge does not equal power: the network redundancy trade-off. Industrial and Coporate Change 17, 903-944.

Reagans, R.E., Zuckerman, E.W., 2008a. All in the family: reply to Burt, Podolny, and van de Rijt, Ban, and Sarkar. Ind Corp Change 17, 979-999.

Rosenkopf, L., Almeida, P., 2003. Overcoming local search through alliances and mobility. Institute for Operations Research and the Management Sciences, pp. 751-766.

Simon, H.A., 1983. Reason in Human Affairs. Basil Blackwell.

Simon, H.A., 1997. Administrative Behavior, 4th Edition ed. Free Press.

Singh, J., 2005. Collaborative Networks as Determinants of Knowledge Diffusion Patterns.

Management Science 51, 756-770.

Singh, J., Sorenson, O., 2007. Science, Social Networks and Spillovers. Industry and Innovation 14, 219-238.

Somaya, D., Williamson, I.O., Lorinkova, N., 2008. Gone but Not Lost: The Different Performance Impacts of Employee Mobility between Cooperators Versus Competitors. Academy of Management Journal 51, 936-953.

Song, J., Almeida, P., Wu, G., 2003. Learning-by-hiring: When is mobility more likely to facilitate interfirm knowledge transfer? Management Science 49, 351-365.

Sorensen, J.B., 1999. Executive migration and interorganizational competition. Social Science Research 28, 289-315.

Sorenson, O., Rivkin, J.W., Fleming, L., 2006. Complexity, networks and knowledge flow. Research Policy 35, 994-1017.

Sorenson, O., Stuart, T.E., 2001. Syndication Networks and the Spatial Distribution of Venture Capital Investments. American Journal of Sociology 106, 1546-1588.

Sorenson, O., Stuart, T.E., 2008. Bringing the context back in: Settings and the search for syndicate partners in venture capital investment networks. Administrative Science Quarterly 53, 266-294.

Stouffer, S.A., 1940. Intervening opportunities: a theory relating mobility and distance. American sociological review 5, 845-867.

Swann, W.B., Milton, L.P., Polzer, J.T., 2000. Should we create a niche or fall in line? Identity negotiation and small group effectiveness. APA American Psychological Association, pp. 238-250.

Uzzi, B., Spiro, J., 2005. Collaboration and creativity: The small world problem. American Journal of Sociology 111, 447-504.

van de Rijt, A., Ban, X., Sarkar, R., 2008. Effective networking when connections are invisible: comment on Reagans and Zuckerman Industrial and Corporate Change 17, 945-952. 
Watts, D.J., Strogatz, S.H., 1998. Collective dynamics of 'small-world' networks. Nature 393, 440442.

Wezel, F.C., Cattani, G., Pennings, J.M., 2006. Competitive implications of interfirm mobility. Organization Science 17, 691-709.

Yakubovich, V., 2005. Weak ties, information, and influence: How workers find jobs in a local Russian labor market. American sociological review 70, 408-421.

Zaheer, A., Soda, G., 2009. Network Evolution: The Origins of Structural Holes. Administrative Science Quarterly 54, 1-31. 
Figure 1. Empirical probability of a tie being formed at time $t$ as a function of the path distance between the organizations at time $t-1$.

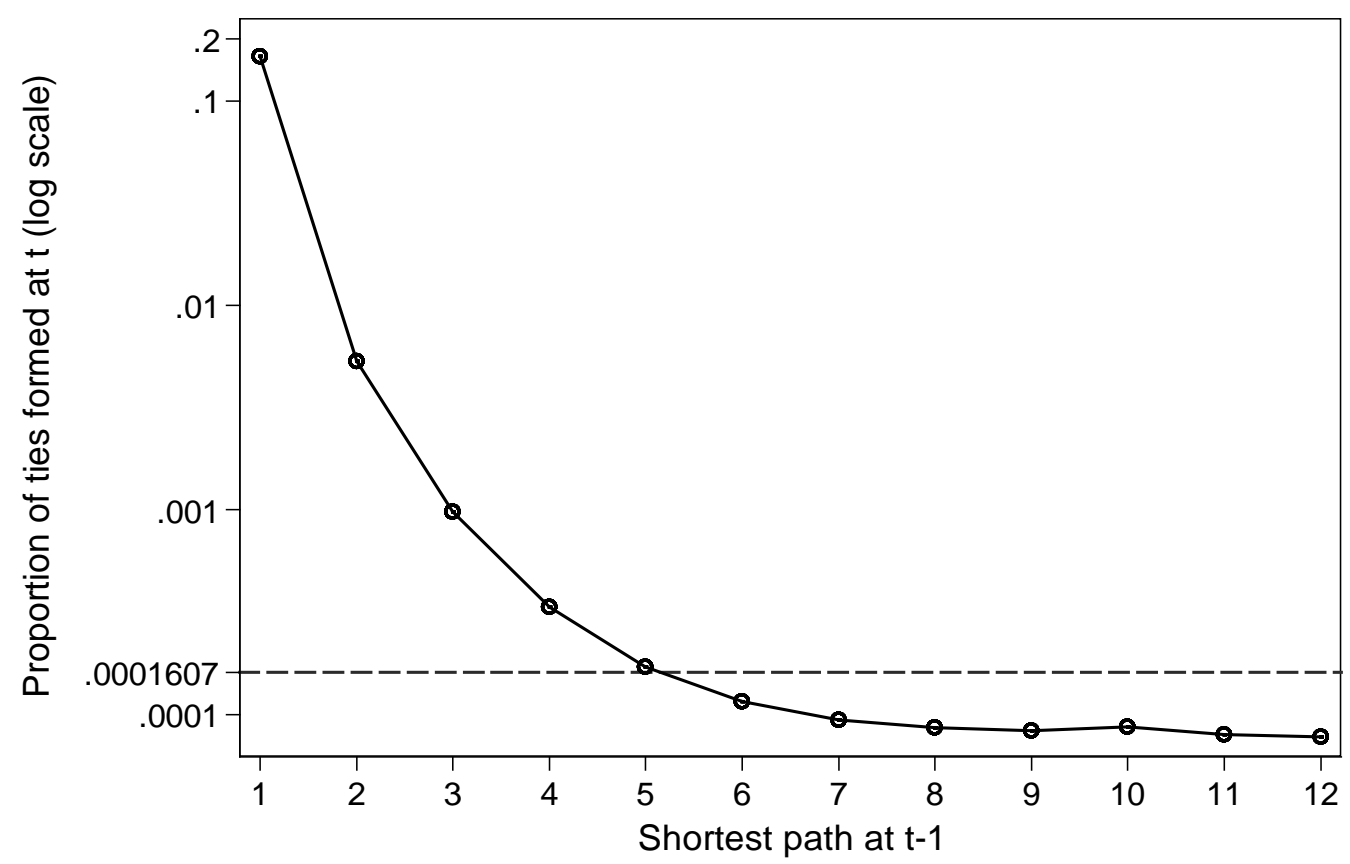


Figure 2. Decreasing odds ratios of lagged structural proximity variables.

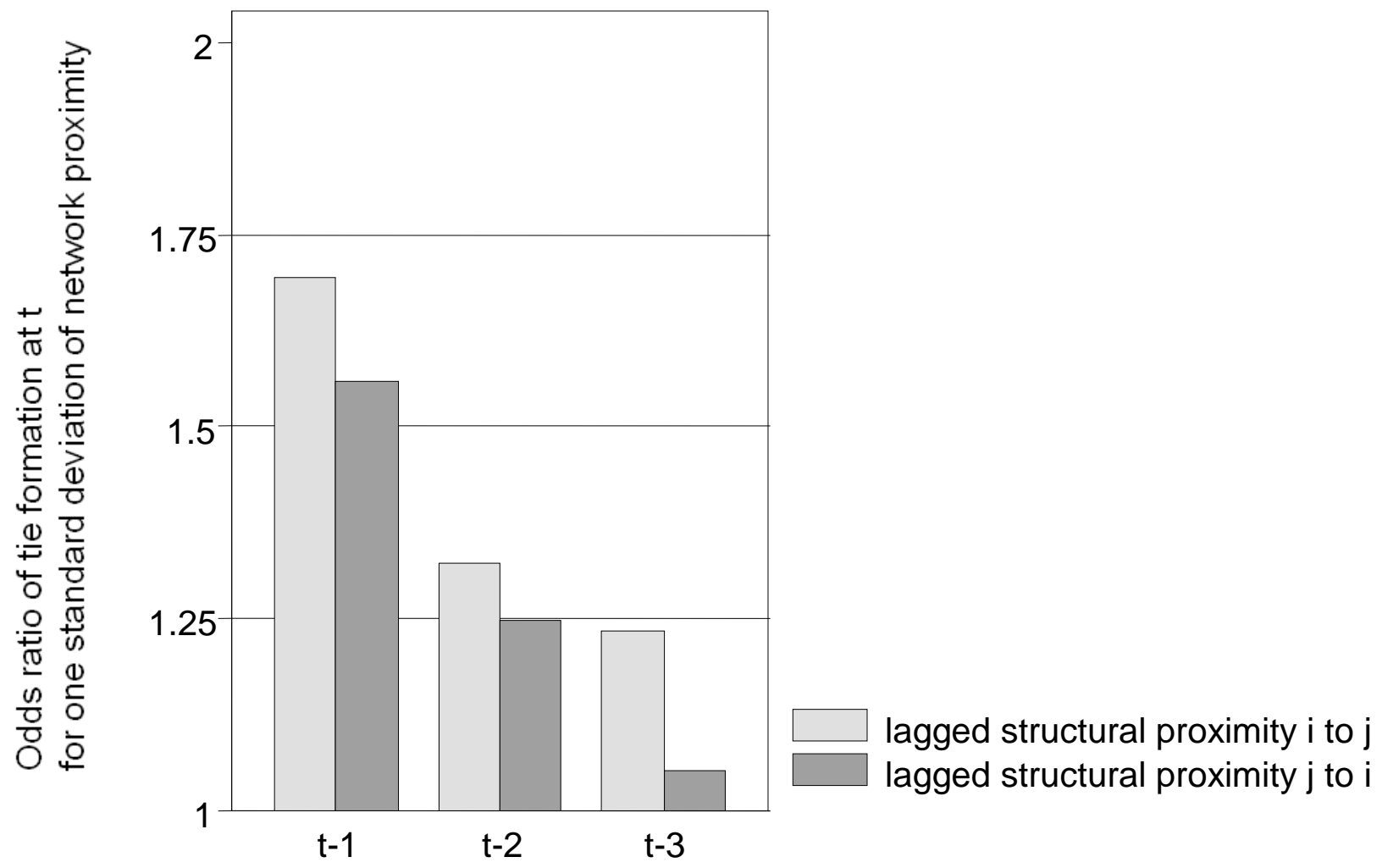


Figure 3. Path distribution of dyads and events.

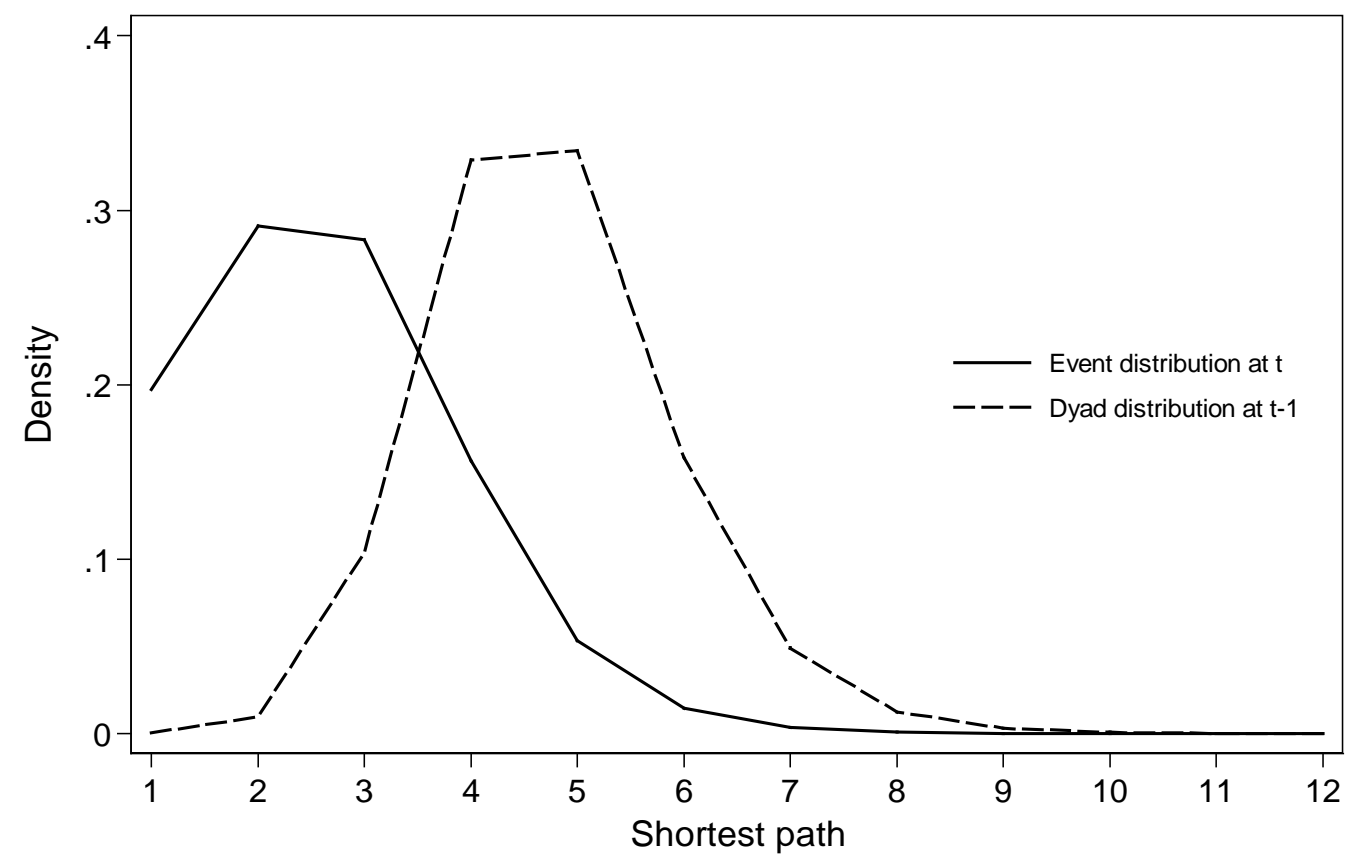


Table 1 Employees' point of view

\begin{tabular}{|c|c|c|}
\hline Time $t$ & $\begin{array}{l}\text { Access to information relevant for } \\
\text { an employee of i for a transition to } \\
j \text { at time } t+1\end{array}$ & Comment \\
\hline Some employees of $\mathbf{i}$ moved to $\mathbf{j}$ & $\begin{array}{l}\text { Employees of } \mathbf{i} \text { can talk with their } \\
\text { former colleagues, whom they know } \\
\text { well and are now working at } \mathbf{j} \text { and } \\
\text { ask them: } \\
\text { a) Whether have heard of any } \\
\text { opening in } \mathbf{j} \text {. } \\
\text { b) Their experience as new } \\
\text { employees of } \mathbf{j}\end{array}$ & \multirow{2}{*}{$\begin{array}{l}\text { Employees of } \mathbf{i} \text { have more } \\
\text { opportunities for hearing } \\
\text { about openings in } \mathbf{j} \\
\text { through former colleagues } \\
\text { who currently work in } \mathbf{j} \\
\text { than through new } \\
\text { colleagues who used to } \\
\text { work in } \mathbf{j} \text {. } \\
\text { Moreover former } \\
\text { employees of } \mathbf{j} \text { are more } \\
\text { likely to talk about what } \\
\text { made them leave } \mathbf{j} \text { than } \\
\text { good reasons to join } \mathbf{j} \text {. }\end{array}$} \\
\hline Some employees of $\mathbf{j}$ moved to $\mathbf{i}$ & $\begin{array}{l}\text { Employees of } \mathbf{i} \text { can talk with their } \\
\text { new colleagues, who used to work } \\
\text { for } \mathbf{j} \text {, and ask them about: } \\
\text { a) Whether they have heard } \\
\text { about openings in } \mathbf{j} \text { through } \\
\text { their former colleagues. } \\
\text { b) Their past experience in } \mathbf{j} \text {. }\end{array}$ & \\
\hline
\end{tabular}


Table 2 Employers' point of view

\begin{tabular}{|c|c|c|}
\hline Time t & $\begin{array}{l}\text { Access to information relevant for } \\
\text { an employer in } j \text { for a recruitment } \\
\text { from i at time } t+1\end{array}$ & Comment \\
\hline Some employees of $\mathbf{j}$ moved to $\mathbf{i}$ & $\begin{array}{l}\text { a) Employers in } \mathbf{j} \text { can talk with } \\
\text { new colleagues who used to } \\
\text { work for i. These new } \\
\text { colleagues are well } \\
\text { positioned to pass on } \\
\text { information about individuals } \\
\text { who want to leave } \mathbf{i} \text {. } \\
\text { b) Employers in } \mathbf{j} \text { have acquired } \\
\text { some knowledge about } \mathbf{i} \text { as a } \\
\text { possible recruitment source. } \\
\text { Employers in } \mathbf{j} \text { can talk with their } \\
\text { former colleagues, who now work in } \\
\mathbf{i} \text { and ask them about: } \\
\text { a) What are their first } \\
\text { impressions about } \mathbf{i} \text {. } \\
\text { b) Whether they have heard } \\
\text { about interesting candidate in } \\
\mathbf{i} \text { through their new } \\
\text { colleagues. }\end{array}$ & $\begin{array}{l}\text { New employees of } \mathbf{j} \text { are } \\
\text { well positioned to } \\
\text { provide information } \\
\text { about who might be } \\
\text { willing to make a move } \\
\text { in } \mathbf{i} \text { to their employers. } \\
\text { By contrast, former } \\
\text { employees of } \mathbf{j} \text { who have } \\
\text { recently joined } \mathbf{i} \text { might } \\
\text { not know their new } \\
\text { colleague well enough to } \\
\text { know who might leave } \\
\text { and make } \\
\text { recommendations. } \\
\text { Given the search cost of } \\
\text { finding new alternatives } \\
\text { (Simon, 1983, 1997), it } \\
\text { is likely that employers } \\
\text { in } \mathbf{j} \text { will look again at } \mathbf{i} \\
\text { as a source of } \\
\text { information for potential } \\
\text { candidates. }\end{array}$ \\
\hline
\end{tabular}


Table 3. Network structure evolution. Descriptive statistics.

\begin{tabular}{|c|c|c|c|c|c|c|c|c|c|c|c|c|c|}
\hline & 1990 & 1991 & 1992 & 1993 & 1994 & 1995 & 1996 & 1997 & 1998 & 1999 & 2000 & 2001 & 2002 \\
\hline \multicolumn{14}{|l|}{ Panel 1: } \\
\hline \multicolumn{14}{|l|}{ Overall network } \\
\hline $\begin{array}{l}\text { Number of } \\
\text { organizations }\end{array}$ & 17,766 & 16,262 & 15,603 & 15,722 & 16,814 & 17,427 & 17,653 & 18,207 & 18,988 & 19,941 & 20,627 & 20,401 & 19,621 \\
\hline Number of links & 54,299 & 37,909 & 42,533 & 43,218 & 54,332 & 56,182 & 55,830 & 63,178 & 69,811 & 79,063 & 87,418 & 72,903 & 64,963 \\
\hline Clustering coefficient & 0.031 & 0.038 & 0.042 & 0.043 & 0.036 & 0.031 & 0.034 & 0.031 & 0.029 & 0.035 & 0.034 & 0.029 & 0.028 \\
\hline Clustering ratio (a) & 0.0051 & 0.0083 & 0.0077 & 0.0078 & 0.0055 & 0.0049 & 0.0054 & 0.0045 & 0.0039 & 0.0044 & 0.0040 & 0.0040 & 0.0042 \\
\hline $\begin{array}{l}\text { Average shortest path } \\
\text { distance }\end{array}$ & 5.4 & 6.2 & 5.9 & 5.8 & 5 & 5.1 & 5.1 & 5 & 4.8 & 4.8 & 4.8 & 5 & 5.1 \\
\hline Path length ratio (b) & 3.9 & 4.5 & 4.3 & 4.2 & 3.6 & 3.7 & 3.7 & 3.6 & 3.5 & 3.4 & 3.4 & 3.6 & 3.7 \\
\hline Degree correlation & 0.029 & 0.069 & 0.082 & 0.056 & 0.049 & 0.029 & 0.03 & 0.027 & 0.015 & 0.022 & 0.02 & 0.028 & 0.036 \\
\hline $\begin{array}{l}\text { Number of } \\
\text { organizations } \\
\text { in the largest } \\
\text { component }\end{array}$ & 17,425 & 15,690 & 14,880 & 15,186 & 16,458 & 17,025 & 17,254 & 17,907 & 18,673 & 19,719 & 20,422 & 20,070 & 19,257 \\
\hline $\begin{array}{l}\text { Average shortest path } \\
\text { in the largest } \\
\text { component }\end{array}$ & 5.4 & 6.2 & 5.9 & 5.8 & 5 & 5.1 & 5.1 & 5 & 4.8 & 4.8 & 4.8 & 5 & 5.1 \\
\hline \multicolumn{14}{|l|}{ Panel 2: } \\
\hline \multicolumn{14}{|l|}{ Less education } \\
\hline $\begin{array}{l}\text { Number of } \\
\text { organizations }\end{array}$ & 16,044 & 14,372 & 13,669 & 13,833 & 14,888 & 15,441 & 15,577 & 16,247 & 16,964 & 17,814 & 18,510 & 17,886 & 16,834 \\
\hline Number of links & 37,363 & 24,755 & 23,159 & 23,041 & 30,671 & 31,932 & 32,001 & 35,769 & 39,820 & 45,851 & 49,756 & 41,766 & 36,536 \\
\hline Clustering coefficient & 0.028 & 0.032 & 0.037 & 0.036 & 0.031 & 0.031 & 0.029 & 0.03 & 0.03 & 0.029 & 0.027 & 0.023 & 0.02 \\
\hline Clustering ratio (a) & 0.0060 & 0.0093 & 0.0109 & 0.0108 & 0.0075 & 0.0075 & 0.0071 & 0.0068 & 0.0064 & 0.0056 & 0.0050 & 0.0049 & 0.0046 \\
\hline Average shortest path & 5.8 & 7.2 & 6.8 & 6.5 & 5.6 & 5.7 & 5.8 & 5.6 & 5.4 & 5.3 & 5.4 & 5.6 & 5.7 \\
\hline Distance & & & & & & & & & & & & & \\
\hline Path length ratio (b) & 4.5 & 5.6 & 5.3 & 5.1 & 4.4 & 4.4 & 4.5 & 4.4 & 4.2 & 4.1 & 4.2 & 4.4 & 4.4 \\
\hline Degree correlation & 0.037 & 0.117 & 0.123 & 0.094 & 0.05 & 0.023 & 0.027 & 0.041 & 0.029 & 0.023 & 0.029 & 0.033 & 0.063 \\
\hline \multicolumn{14}{|l|}{ Panel 3: } \\
\hline \multicolumn{14}{|l|}{ More education } \\
\hline $\begin{array}{l}\text { Number of } \\
\text { organizations }\end{array}$ & 9,493 & 8,268 & 8,401 & 8,667 & 9,818 & 10,050 & 10,373 & 10,889 & 11,502 & 12,443 & 13,333 & 12,867 & 12,435 \\
\hline Number of links & 17,787 & 14,087 & 13,444 & 14,336 & 19,385 & 19,942 & 21,017 & 23,291 & 25,961 & 30,591 & 34,978 & 28,703 & 26,106 \\
\hline Clustering coefficient & 0.035 & 0.044 & 0.042 & 0.043 & 0.04 & 0.04 & 0.041 & 0.037 & 0.036 & 0.04 & 0.036 & 0.034 & 0.029 \\
\hline Clustering ratio (a) & 0.0093 & 0.0129 & 0.0131 & 0.0130 & 0.0101 & 0.0101 & 0.0101 & 0.0086 & 0.0080 & 0.0081 & 0.0069 & 0.0076 & 0.0069 \\
\hline Average shortest path & 5.9 & 6.5 & 6.2 & 6 & 5.2 & 5.4 & 5.2 & 5.3 & 5.1 & 5.1 & 5.1 & 5.3 & 5.5 \\
\hline \multicolumn{14}{|l|}{ Distance } \\
\hline Path length ratio (b) & 4.6 & 5.1 & 4.8 & 4.7 & 4.0 & 4.2 & 4.0 & 4.1 & 4.0 & 4.0 & 4.0 & 4.1 & 4.3 \\
\hline Degree correlation & 0.035 & 0.044 & 0.042 & 0.043 & 0.04 & 0.04 & 0.041 & 0.037 & 0.036 & 0.04 & 0.036 & 0.034 & 0.035 \\
\hline
\end{tabular}

(a) Clustering Ratio=1/N*(C/Cr) with $\mathrm{N}$, network size, C observed clustering coefficient, Cr Clustering coefficient for a random network of equivalent size.

(b)Path Length Ratio=ln(N)*(L/Lr) with N, network size, L observed average path length, Lr average path length for a random network of equivalent size. 
Table 4. Description of covariates included in logit models (overall network).

\begin{tabular}{|c|c|c|}
\hline Description of the variable & Mean & $\begin{array}{r}\text { Standard } \\
\text { Deviation }\end{array}$ \\
\hline $\begin{array}{l}\text { Total number of employees in } \\
\text { organization } i\end{array}$ & 87.97 & 387.20 \\
\hline $\begin{array}{l}\text { Total number of employees } \\
\text { in organization } j\end{array}$ & 93.94 & 400.17 \\
\hline $\begin{array}{l}\text { Absolute difference in percentage of women } \\
\text { in organization } i \text { and } j\end{array}$ & 0.24 & 0.21 \\
\hline $\begin{array}{l}\text { Absolute difference in percentage of non-Swedish- } \\
\text { born in organization } i \text { and } j\end{array}$ & 0.18 & 0.27 \\
\hline $\begin{array}{l}\text { Absolute difference in average age of employees } \\
\text { in organization } i \text { and } j\end{array}$ & 5.68 & 4.48 \\
\hline $\begin{array}{l}\text { Absolute difference in average years } \\
\text { of schooling of employees in organization } i \text { and } j\end{array}$ & 1.25 & 1.02 \\
\hline $\begin{array}{l}\text { Organization } i \text { and } j \text { are part } \\
\text { of same multi-organizational firm }\end{array}$ & 0.07 & 0.26 \\
\hline $\begin{array}{l}\text { Organization } i \text { and } j \text { are in } \\
\text { the same geographic area (municipality) }\end{array}$ & 0.33 & 0.47 \\
\hline Average earnings in organization $i$ (1000 SEK) & 196.612 & 105.866 \\
\hline Average earnings in organization $j$ (1000 SEK) & 209.091 & 108.035 \\
\hline $\begin{array}{l}\text { Indegree of organization } j \text { (measured as the number } \\
\text { of individuals who moved to organization } j \text { from } \\
\text { organizations other than } j \text { during the year). }\end{array}$ & 21.92 & 194,08 \\
\hline $\begin{array}{l}\text { Network proximity calculated along the path from } \\
\text { organization } i \text { to } j \text { (see Methods for definition) }\end{array}$ & 0.056 & 0.076 \\
\hline $\begin{array}{l}\text { Structural proximity calculated along the path from } \\
\text { organization } j \text { to } i \text { (see Methods for definition) }\end{array}$ & 0.056 & 0.078 \\
\hline Structural proximity $\mathrm{i} \rightarrow \mathrm{j}$ at $\mathrm{t}-2$ & 0.027 & 0.056 \\
\hline Structural proximity $\mathrm{j} \rightarrow \mathrm{i}$ at $\mathrm{t}-2$ & 0.026 & 0.056 \\
\hline Structural proximity $\mathrm{i} \rightarrow \mathrm{j}$ at $\mathrm{t}-3$ & 0.022 & 0.051 \\
\hline Structural proximity $\mathrm{j} \rightarrow \mathrm{i}$ at $\mathrm{t}-3$ & 0.019 & 0.048 \\
\hline
\end{tabular}


Table 5. Matched case-control conditional logit models.

\begin{tabular}{|c|c|c|c|c|c|}
\hline & \multicolumn{3}{|c|}{ Overall network } & \multirow{2}{*}{$\begin{array}{l}\text { Less } \\
\text { educated }\end{array}$} & \multirow{2}{*}{$\begin{array}{l}\text { More } \\
\text { educated } \\
\text { (5) }\end{array}$} \\
\hline & (1) & (2) & & & \\
\hline 1. Total number of employees in organization $i$ & $\begin{array}{l}0,002 \\
(107.09)\end{array}$ & $\begin{array}{l}0,002 \\
(103.92)\end{array}$ & $\begin{array}{l}0,001 \\
(70.09)\end{array}$ & $\begin{array}{l}0,002 \\
(86.87)\end{array}$ & $\begin{array}{l}0,001 \\
(72.97)\end{array}$ \\
\hline 2. Total number of employees in organization $j$ & $\begin{array}{l}0,002 \\
(102.99)\end{array}$ & $\begin{array}{l}0,002 \\
(95.59)\end{array}$ & $\begin{array}{l}0,0002 \\
(9.57)\end{array}$ & $\begin{array}{l}0,001 \\
(67.29)\end{array}$ & $\begin{array}{l}0,001 \\
(62.59)\end{array}$ \\
\hline 3. Product of variable 1 and variable $2(\times .0001)$ & $\begin{array}{l}0,723 \\
(46.82)\end{array}$ & $\begin{array}{l}0,856 \\
(46.4)\end{array}$ & $\begin{array}{l}0,672 \\
(33.82)\end{array}$ & $\begin{array}{l}0,422 \\
(25.03)\end{array}$ & $\begin{array}{l}0,347 \\
(27.04)\end{array}$ \\
\hline $\begin{array}{l}\text { 4. Absolute difference in percentage of women } \\
\text { in organization } i \text { and } j\end{array}$ & $\begin{array}{l}-2,110 \\
(-155.10)\end{array}$ & $\begin{array}{l}-2,106 \\
(-152.96)\end{array}$ & $\begin{array}{l}-2,198 \\
(-128.81)\end{array}$ & $\begin{array}{l}-2,003 \\
(-124.12)\end{array}$ & $\begin{array}{l}-2,459 \\
(-105.55)\end{array}$ \\
\hline 5. Absolute difference in percentage of non-Swedish- & $-0,301$ & $-0,397$ & $-1,490$ & $-0,529$ & $-0,247$ \\
\hline born employees in organization $i$ and $j$ & $(-28.62)$ & $(-34.32)$ & $(-74.23)$ & $(-37.00)$ & $(-14.46)$ \\
\hline 6. Absolute difference in average age of employees & $-0,055$ & $-0,056$ & $-0,054$ & $-0,053$ & $-0,062$ \\
\hline in organization $i$ and $j$ & $(-100.72)$ & $(-99.40)$ & $(-77.01)$ & $(-78.49)$ & $(-67.52)$ \\
\hline 7. Absolute difference in average years of schooling & $-0,479$ & $-0,479$ & $-0,448$ & $-0,423$ & $-0,331$ \\
\hline between employees in organization $i$ and $j$ & $(-172.26)$ & $(-170.00)$ & $(-131.69)$ & $(-118.13)$ & $(-76.94)$ \\
\hline 8. Organization $i$ and $j$ are part of the same & 2,574 & 2,618 & 2,492 & 3,040 & 2,526 \\
\hline Multi-organizational firm & $(214.87)$ & $(200.94)$ & $(167.55)$ & $(175.1)$ & $(162.78)$ \\
\hline $\begin{array}{l}\text { 9. Organization } i \text { and } j \text { are located in the same } \\
\mathrm{m}\end{array}$ & $\begin{array}{l}0,642 \\
(133.55)\end{array}$ & $\begin{array}{l}0,638 \\
(130.8)\end{array}$ & $\begin{array}{l}0,635 \\
(102.90)\end{array}$ & $\begin{array}{l}0,715 \\
(120.76)\end{array}$ & $\begin{array}{l}0,516 \\
(68.42)\end{array}$ \\
\hline 10. Average earnings in organization $i$ (1000 SEK) & $\begin{array}{l}-0,009 \\
(-30.67)\end{array}$ & $\begin{array}{l}-0,010 \\
(-32.70)\end{array}$ & $\begin{array}{l}-0,016 \\
(-38.42)\end{array}$ & $\begin{array}{l}-0,002 \\
(-45.22)\end{array}$ & $\begin{array}{l}-0,018 \\
(-4.84)\end{array}$ \\
\hline 11. Average earnings in organization $i$ (1000 SEK) & $\begin{array}{l}0,003 \\
(11.89)\end{array}$ & $\begin{array}{l}-0,002 \\
(-9.11)\end{array}$ & $\begin{array}{l}-0,002 \\
(-6.09)\end{array}$ & $\begin{array}{l}-0,005 \\
(-10.58)\end{array}$ & $\begin{array}{l}0,016 \\
(4.17)\end{array}$ \\
\hline 12. Indegree of organization $j$ & $\begin{array}{l}0,002 \\
(57.48)\end{array}$ & $\begin{array}{l}0,002 \\
(55.24)\end{array}$ & $\begin{array}{l}0,032 \\
(67.60)\end{array}$ & $\begin{array}{l}0,005 \\
(34.46)\end{array}$ & $\begin{array}{l}0,003 \\
(32.99)\end{array}$ \\
\hline $\begin{array}{l}\text { 13. Structural proximity along path from organization } \\
i \text { to } j\end{array}$ & 8,466 & 8,031 & 6,588 & 7,907 & 4,481 \\
\hline (see Appendix for definition) & $(192.71)$ & $(157.62)$ & $(118.05)$ & $(54.68)$ & $(25.47)$ \\
\hline $\begin{array}{l}\text { 14. Structural proximity along path from organization } \\
j \text { to } i\end{array}$ & 6,766 & 6,842 & 5,546 & 7,379 & 7,298 \\
\hline (see Appendix for definition) & $(167.32)$ & $(162.33)$ & $(109.93)$ & $(128.7)$ & $(102.44)$ \\
\hline 15. Structural proximity $\mathrm{i} \rightarrow \mathrm{j}$ at $(\mathrm{t}-2)$ & & & $\begin{array}{l}3,479 \\
(58.24)\end{array}$ & & \\
\hline 16. Structural proximity $\mathrm{j} \rightarrow \mathrm{i}$ at $(\mathrm{t}-2)$ & & & $\begin{array}{l}2,762 \\
(48.70)\end{array}$ & & \\
\hline 17. Structural proximity $\mathrm{i} \rightarrow \mathrm{j}$ at $(\mathrm{t}-3)$ & & & $\begin{array}{l}2,627 \\
(40.01)\end{array}$ & & \\
\hline 18. Structural proximity $\mathrm{j} \rightarrow \mathrm{i}$ at $(\mathrm{t}-3)$ & & & $\begin{array}{l}0,658 \\
(10.38)\end{array}$ & & \\
\hline Number of observations & 2.359 .022 & 2.083.381 & 1.811 .677 & 1.413 .556 & 1.018 .749 \\
\hline Log likelihood & -389.469 & -376.666 & -241.613 & -249.333 & -167.299 \\
\hline Pseudo R2 & 0,480 & 0,435 & 0,512 & 0,453 & 0,483 \\
\hline
\end{tabular}

